\title{
Non-thermal atmospheric pressure plasma jet applied to inactivation of different microorganisms
}

\author{
T.M.C. Nishime ${ }^{\text {a,* }}$, A.C. Borges ${ }^{\text {b }}$, C.Y. Koga-Ito ${ }^{\text {b }}$, M. Machida ${ }^{c}$, L.R.O. Hein ${ }^{a}$, K.G. Kostov ${ }^{\text {a }}$ \\ a São Paulo State University - UNESP, Campus in Guaratinguetá - FEG, Guaratinguetá, SP 12516-410, Brazil \\ b São Paulo State University - UNESP, Institute of Science and Technology - ICT, São José dos Campos, SP 12247-004, Brazil \\ c Campinas State University -UNICAMP, Physics Institute - IFGW, Campinas, SP 13083-859, Brazil
}

\section{A R T I C L E I N F O}

Article history:

Received 14 March 2016

Revised 22 July 2016

Accepted in revised form 26 July 2016

Available online 27 July 2016

\section{Keywords:}

Plasma jet

Cold atmospheric plasma

Decontamination

\begin{abstract}
A B S T R A C T
Non-thermal atmospheric pressure plasma jets (APPJs) are capable of generating cold plasma plumes that are not confined by electrodes, which makes them very attractive for bio-medical applications. In the present work, the inactivation efficiency of cold APPJ was evaluated against three pathogenic microorganisms with different cell wall characteristics. The Gram-positive bacterium Enterococcus faecalis (ATCC 29212), the Gram-negative bacterium Pseudomonas aeruginosa (ATCC 15442) and the fungus Candida albicans (SC 5314) were plated on standard Petri dishes filled with specific culture media. The plasma jet with mean power of $1.8 \mathrm{~W}$ was directed perpendicularly on agar plates and the system was flushed with pure helium at two different flows, 2.0 and 4.0 SLM. During the treatments, time and distance between nozzle and agar were varied. The presence of excited reactive species was confirmed by optical emission spectroscopy. Scanning electron microscopy (SEM) was applied for investigation of cell morphology. The microbicidal efficiency was evaluated by measuring the area of inhibition zone (where there was no cell growth). For different flows of helium, no significant difference of inhibition zone size was noted for the same microbial species. However, high flows led to formation of non-homogenous inhibition zones, presenting microcolonies distributed through the inactivated region. The Gram-positive bacterium was more susceptible to the plasma antimicrobial effects than the other microorganisms.
\end{abstract}

(c) 2016 Elsevier B.V. All rights reserved.

\section{Introduction}

Non-thermal atmospheric pressure plasmas have attracted much attention due to their innumerous advantages over low-pressure plasmas [1-4]. Since they can be generated under ambient pressure and temperature conditions there is no limitation in the size of the treated objects $[3,4]$. Cold atmospheric pressure plasmas are also characterized by reactive chemistry at close-to-room temperature, which allows the treatment of heat sensitive materials [3].

Among other plasma sources, the atmospheric pressure plasma jet has emerged as a promising tool capable of generating cold plasma plumes that are not spatially confined by electrodes. Depending on the operation conditions, the resulting plasma jet can propagate up to several centimeters into surrounding ambient, which makes it appropriate for treating irregular surfaces or 3D objects [4]. Plasma jets present relatively low operational cost and when launched into air generate large amount of reactive and exited species under ambient temperature conditions. Because of their rich chemistry and the possibility for easy

\footnotetext{
* Corresponding author.

E-mail address: mayumi.nishime@gmail.com (T.M.C. Nishime).
}

application to any target, APPJs have become very attractive for biomedical applications [5-8]. They have drawn significant attention in applications such as microbial inactivation [9-11], blood coagulation [12], decontamination of medical equipment [13], wound healing [14], for medical therapy and applications in dentistry $[15,16]$.

Most APPJ systems consist of a high voltage electrode embedded in a dielectric tube or a capillary. The device is fed with a noble gas or a mixture of a noble and a reactive gas. The plasma is generated inside the tube and expands into the open air where the plasma plume interacts with air molecules forming reactive oxygen (ROS) and nitrogen species (RNS) [17]. These reactive species combined with UV photons and charged particles can cause microbial inactivation. Besides, humidity present in air can enhance the production of ROS by the plasma jet [18]. The exact mechanism of cell inactivation by cold plasma jet as well as the precise contribution of each plasma component to the process are not well-understood [19]. The damaging effects of reactive oxygen and nitrogen species (RONS) on cells can be attributed to their ability of reacting with some cellular biomacromolecules such as proteins, lipids and DNA [20]. Some ROS can cause oxidative damage to microorganisms [21]. However, it is important to consider the synergetic effect of multiple species presented in APPJs. It was shown 
that jet inactivation efficiency is greatly enhanced in the presence of UV radiation [19].

The precise control of plasma parameters is an important concern in plasma medicine. When physical parameters are changed, different amount of plasma species are driven to target, which can lead to more efficient surface decontamination. In the present work, three species representative of different microbial groups were treated in order to evaluate the inactivation efficiency of cold atmospheric pressure plasma jet. Gram-positive bacteria possess thick cell walls composed by several layers of peptidoglycan. Differently from Gram-negative bacteria, they are absent of bacterial outer membrane. Gram-negative bacteria exhibit clearly layered structure with three main sections: the outer membrane, the peptidoglycan cell wall and the inner membrane. The outer membrane plays important role in protecting the cell against toxic molecules and providing an extra stabilizing layer around the cell [22]. Fungi are eukaryotic cells and their cell walls are completely different from the prokaryotic ones (bacteria). Fungal cell walls are very thick and composed by rigid polysaccharide layers, such as chitin. It is responsible for providing structural strength to fungi cell walls making them more resistant to harmful extracellular agents [23]. Due to these noticeable structural differences of the selected microorganisms, it is expected that different responses to the plasma treatment would occur. Here, the Gram-positive bacterium Enterococcus faecalis (ATCC 29212), the Gram-negative bacterium Pseudomonas aeruginosa (ATCC 15442) and the fungus Candida albicans (SC 5314) were plated on standard Petri dish filled with culture media and then exposed to plasma. The effect of gas flow and the distance between plasma plume and agar surface was also investigated.

\section{Materials and methods}

\subsection{Plasma generation}

The atmospheric pressure plasma jet used in this study is a DBD type APPJ with a single electrode and it was detailed in [24]. It consists of a $2.3 \mathrm{~mm}$ diameter copper rod, which is embedded inside a closed-end quartz tube. The quartz tube with wall thickness of $1.7 \mathrm{~mm}$ serves as a dielectric barrier. It is centered in a syringe-like dielectric enclosure made of Delrin, which terminated with $2.0 \mathrm{~cm}$ long, $1.5 \mathrm{~mm}$ inner diameter nozzle. The system is flushed with helium (99.5\% purity) and gas flow rate was adjusted within the range 0.1-10.0 SLM by a rotameter.

The electrode is connected to a Minupuls4 AC power supply (GBS Elektronik GmbH, Germany). A grounded sample holder was placed under the plasma plume allowing fine vertical displacement of the sample and electrical characterization of the discharge. The discharge current and the transferred charge were measured across a low inductance resistor of $100 \Omega$ (for current) or a capacitor of $10 \mathrm{nF}$ (for transferred charge) connected in series to the grounded stage. The signals were monitored on a digital oscilloscope (Tektronix TDS 2024B, $200 \mathrm{MHz}$ ). The mean discharge power of the plasma jet (1.8 W) was calculated by the Q-V Lissajous figure method. More detailed information about electrical characterization of the plasma jet can be found in [24].

\subsection{Microorganisms}

The following microorganisms were used in this study: Enterococcus faecalis ATCC 29212, Pseudomonas aeruginosa ATCC 15442 and Candida albicans SC 5314. All organisms were kept in BHI broth supplemented with $20 \%$ glycerol at $-80^{\circ} \mathrm{C}$. Fresh cultures were obtained by plating C. albicans on Sabouraud dextrose agar, E. faecalis on M-enterococcus and $P$. aeruginosa on BHI agar. After incubation for $24 \mathrm{~h}$ at $37{ }^{\circ} \mathrm{C}$ and normoxia, cells were suspended in saline solution ( $\mathrm{NaCl} 0.9 \%$ ) and the turbidity was adjusted to the McFarland 0.5 standard. To evaluate the antimicrobial effect of plasma jet, $0.1 \mathrm{~mL}$ of cells suspensions were plated on the surface of solid culture medium distributed in standard Petri dishes (90 mm diameter) using a sterile swab. Dishes were kept in aseptic environment (air flow chamber) to dry for $15 \mathrm{~min}$ and then exposed to plasma jet. In order to evaluate the effect of plasma treatment on cells, the area of microbial inhibition zones formed on agar were calculated.

\subsection{Treatment conditions}

Plasma jet operated at frequency of $31.0 \mathrm{kHz}$ and voltage amplitude of $13.0 \mathrm{kV}$ for all treatments. Each experiment was performed in triplicate in order to ensure reproducibility and the plasma plume was directed perpendicularly to the surfaces of agar plates. The three microorganisms were exposed to plasma jet for different time intervals $(60,90,120,150$ and $180 \mathrm{~s})$. After treatment, all plates were incubated for $24 \mathrm{~h}$ at $37^{\circ} \mathrm{C}$. For control experiments, samples were subjected to helium flow at the same flow rate without plasma ignition.

The effect of gas flow on inactivation of different microorganisms was studied by varying the applied helium flow between 2.0 and 4.0 SLM. This flow range was determined according to the conditions to obtain optimal jet length (around $2.0 \mathrm{~cm}$ ). In this first experiment, the distance between the agar surface and nozzle exit was kept fixed to $2.5 \mathrm{~cm}$. Since increase of treatment distance can prevent some active species of reaching the surface, a second experiment was done. The distance between nozzle and agar was varied while the gas flow was kept constant in 2.0 SLM. The treatments were performed with three different distances $(2.0,2.5$ and $3.0 \mathrm{~cm})$.
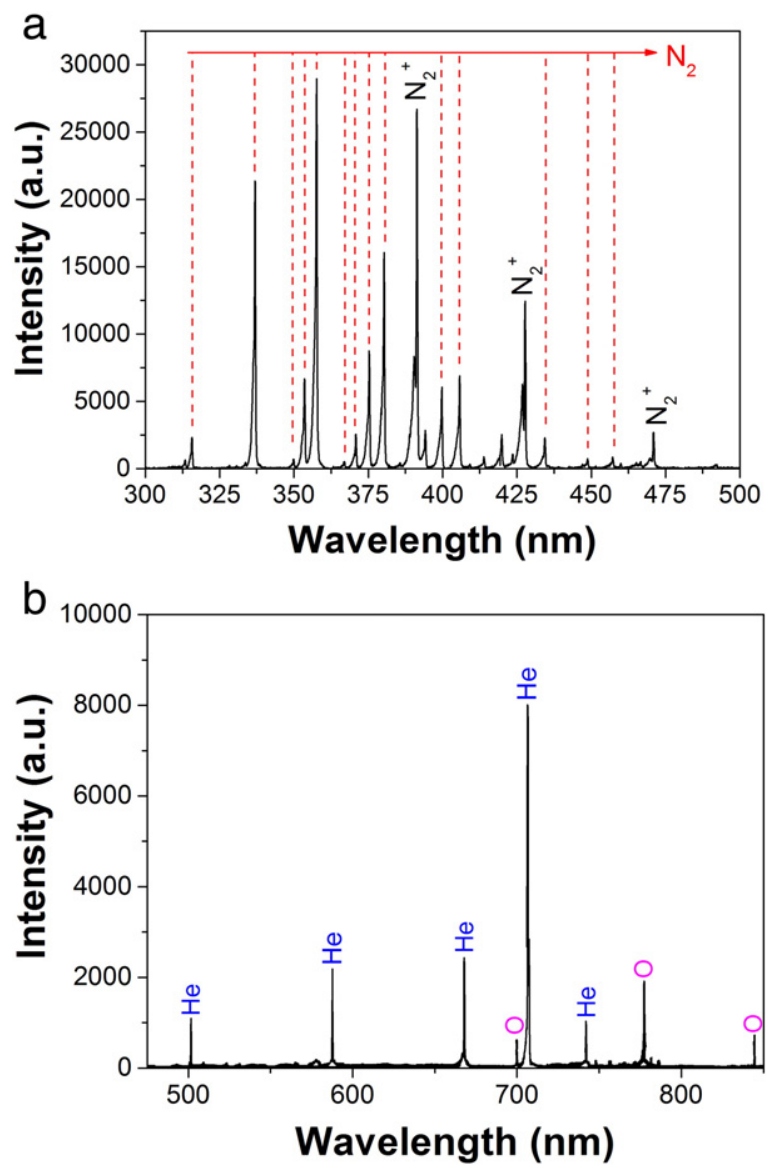

Fig. 1. Emission spectrum acquired at the tip of the plasma plume (a) for wavelengths below $500 \mathrm{~nm}$ and (b) for wavelengths between $475 \mathrm{~nm}$ and $850 \mathrm{~nm}$. 


\subsection{Scanning electron microscopy analysis (SEM)}

After exposure to plasma all microorganisms were subjected to SEM analysis in order to investigate possible cell damages. Ten microliters of cells suspensions were transferred to glass slides and exposed to plasma jet for $120 \mathrm{~s}$. After treatment, glass slides were maintained in $2 \%$ glutaraldehyde solution for $2 \mathrm{~h}$. Then, the slides were washed with saline solution, after that exposed consequently to $25 \%, 50 \%$ and $75 \%$ ethanol solutions for $20 \mathrm{~min}$ in each and finally immersed in $100 \%$ ethanol for $1 \mathrm{~h}$. After drying for $24 \mathrm{~h}$ at $28{ }^{\circ} \mathrm{C}$, a thin golden layer was deposited
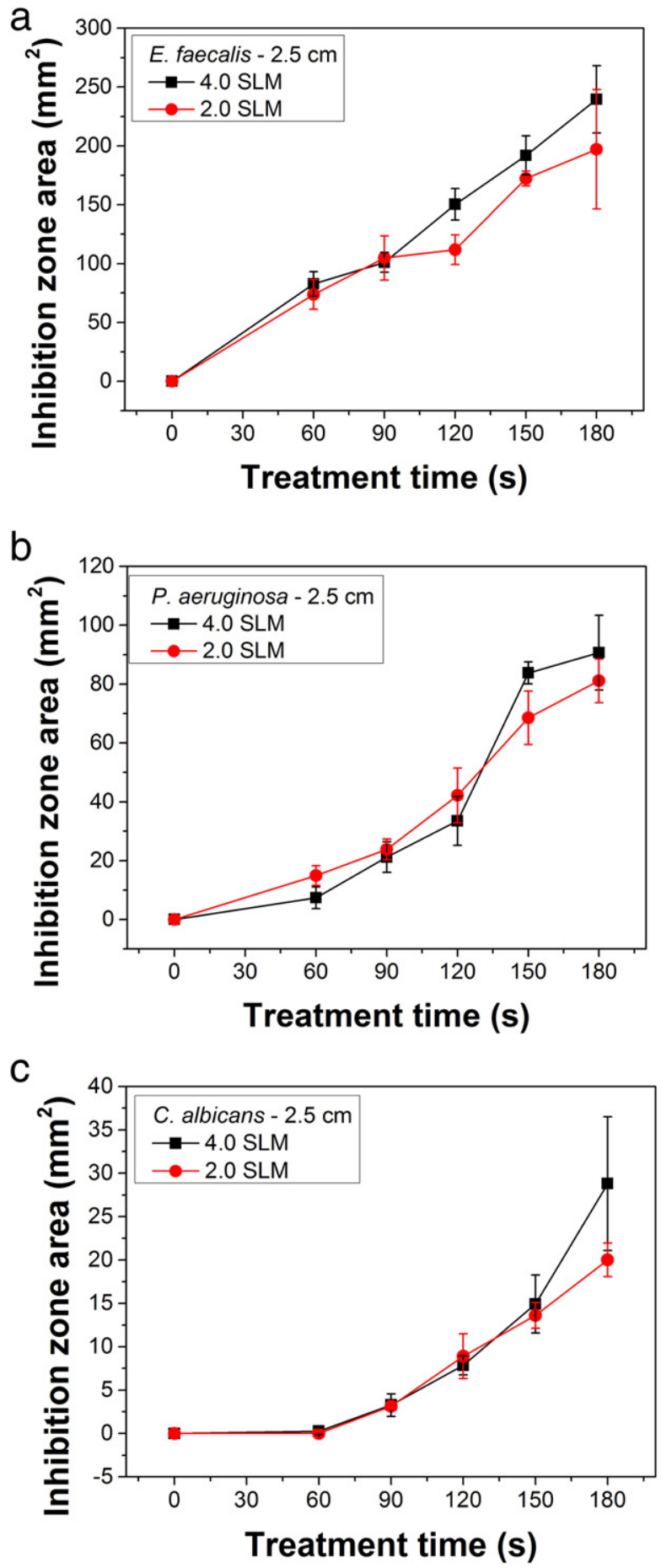

Fig. 2. Comparison of the inhibition zone area at two different flow rates after treatment of (a) Enterococcus faecalis, (b) Pseudomonas aeruginosa and (c) Candida albicans with plasma jet. over the samples to avoid surface charging during SEM analysis. All samples were mounted on aluminum stubs and examined by a scanning electron microscope (Zeiss, EVO LS 15). The microscope operated at low pressure with a tungsten filament and the samples were scanned by a $3.0 \mathrm{kV}$ beam at a work distance of $10.0 \mathrm{~mm}$. The aperture size was kept in $30.0 \mu \mathrm{m}$ and images were captured with magnification of $20,000 \times$.

\subsection{Optical emission spectroscopy (OES)}

Characteristic emissions of the plasma plume were investigated by an optical emission spectrometer (Andor Technology Shamrock 303i). The spectra were collected using a system of collimating lens placed perpendicularly to the jet axis. Spectra were recorded in the wavelength range from $300 \mathrm{~nm}$ to $850 \mathrm{~nm}$ using grating of $1200 \mathrm{~g} / \mathrm{mm}$, slit of $155 \mu \mathrm{m}$ and integration time of $1.0 \mathrm{~s}$.

\section{Results and discussion}

The helium plasma generated by the APPJ expands to the surrounding air and interacts with air molecules, such as $\mathrm{O}_{2}, \mathrm{~N}_{2}$ and humidity, forming reactive species. Optical emission spectroscopy was used to identify the excited species in the plasma plume. The spectrum acquired at the tip of the plasma jet is shown in Fig. 1. Characteristic spectral lines of He can be observed in the range between 500 and $750 \mathrm{~nm}$. The intense emission lines of $\mathrm{N}_{2}$ and $\mathrm{N}_{2}^{+}$prove the efficient interaction of energetic plasma species with air molecules. Also, the presence of ROS is evidenced by the weak $\mathrm{O}$ I emissions at 700,777 and $844 \mathrm{~nm}$. The presence of these lines confirms the energy transfer from excited He atoms and metastables to nitrogen and oxygen molecules leading to formation of reactive oxygen and nitrogen species (RONS) [25].

The antimicrobial efficiency of our atmospheric pressure plasma jet was tested against three common pathogenic microorganisms: the Gram-positive bacterium E. faecalis, the Gram-negative bacterium $P$. aeruginosa and the yeast $C$. albicans. Some long-living species, such as $\mathrm{O}$ and $\mathrm{O}_{3}$, can diffuse outward covering large area. In fact, it was observed that the size of inhibition zones was always bigger than the plasma jet diameter, suggesting that inactivation occurred mostly due to the action of ROS. It was shown in [24] that the inhibition zone diameter increased with increasing the exposure time until saturation is reached. Since active species have a limited lifetime, they cannot cover larger areas of the sample even the treatment time is further increased.

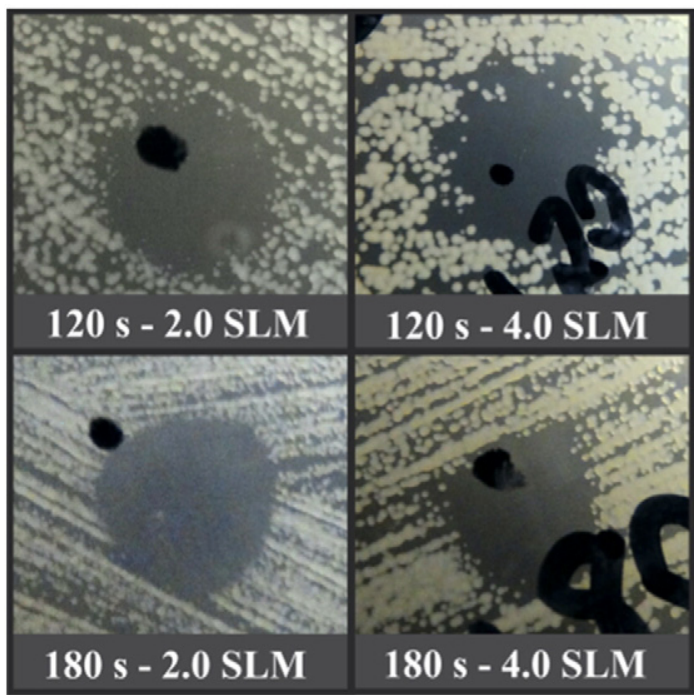

Fig. 3. Inhibition zones irregularities of $C$. albicans observed for treatments with high flow rate for $120 \mathrm{~s}$ and $180 \mathrm{~s}$. 
The gas flow is an important parameter that determines the velocity with which the active species are driven to target. Depending on the flow rate, some short-living species may not reach the sample. Besides of transporting radicals and active species close to the surface the gas flow also has a cooling effect [26,27].

To determine the role of gas flow in the antimicrobial effect of plasma jet, the three microorganisms were exposed to plasma using different flow rates. The variation of inhibition zone size of all organisms treated at a distance of $2.5 \mathrm{~cm}$ for two different gas flows is given in Fig. 2(a)-(c). For all treatment times there was no significant difference

\section{a}

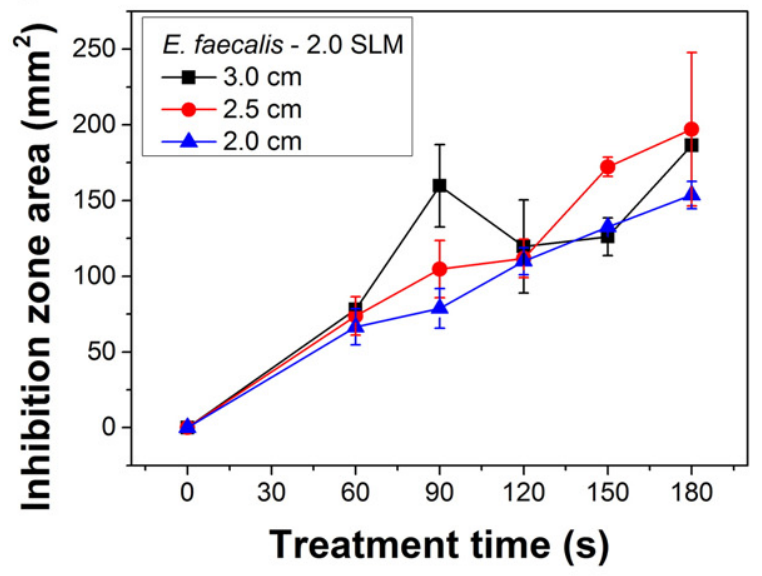

b

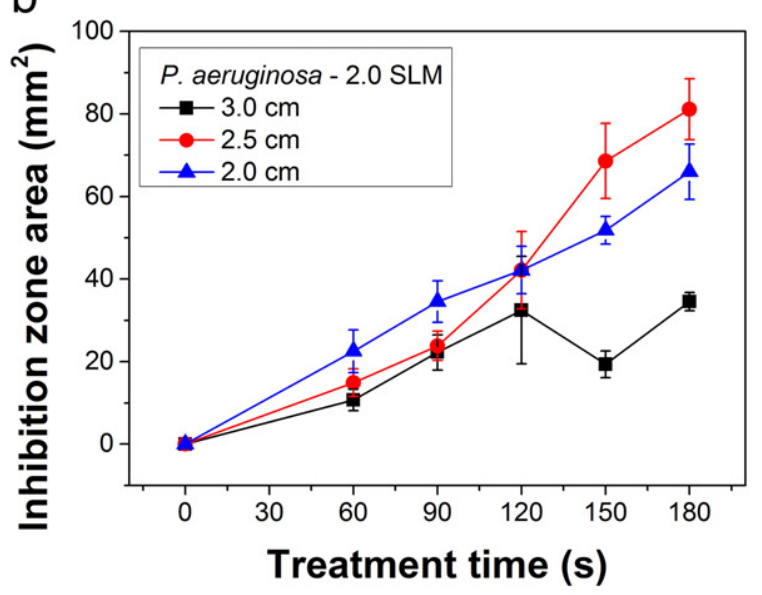

C

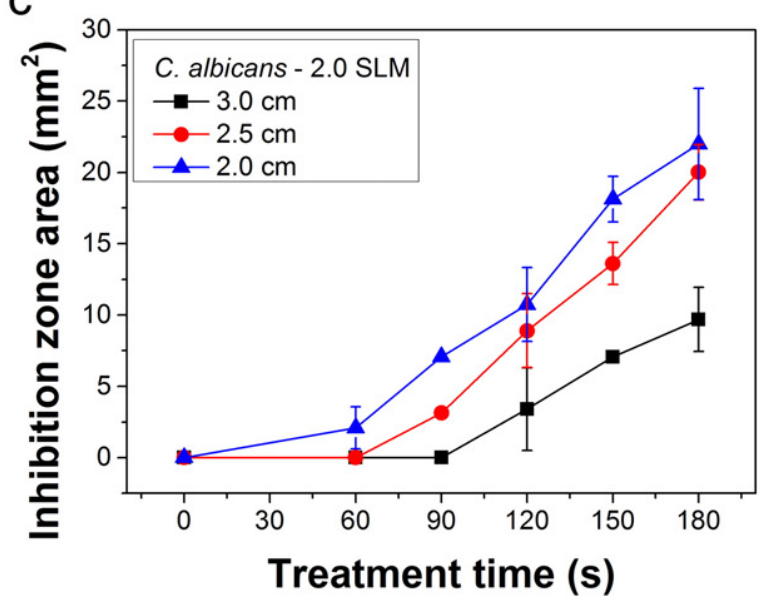

Fig. 4. Effect of distance variation on inhibition efficiency of (a) E. faecalis, (b) P. aeruginosa and (c) C. albicans. in the size of inhibition zones when the flow rate is increased from 2.0 SLM to 4.0 SLM. However, as reported in [27] the zones shape and homogeneity were compromised at higher flows. In our experiments at $4.0 \mathrm{SLM}$ all three microorganisms presented irregularities on the edge of inhibition zones. According to [27], at high gas flow rates the flow dynamics effects, such as turbulent mixing and buoyancy effect play important role in active species formation and distribution, thus governing the inhibition zones shape and uniformity. As observed in our experiments and showed in Fig. 3, at 4.0 SLM the inhibition zones exhibit irregular shapes. Therefore, to evaluate better the jet inactivation efficiency we chose as parameter for comparison the area of inhibition zone instead of its diameter. In order to reduce measurements uncertainty and determine more precisely the area of irregular zones, the calculation was performed by means of image software.

Variation of distance between the jet nozzle and the sample resulted in different doses of photons and reactive species that can reach the surface. UV radiation intensity decreases with the squared distance and ions can recombine quickly outside the electric field [28]. Keeping the flow rate fixed at 2.0 SLM, the distance to the samples was varied between 2.0 and $3.0 \mathrm{~cm}$ and the results are shown in Fig. 4. The Grampositive and Gram-negative bacteria, presented in Fig. 4(a) and (b) respectively, did not exhibit clear dependence on the distance variation. Especially for treatment time below $120 \mathrm{~s}$ the distance does not seems to affect the inhibition zones area. However, the yeast showed a clear tendency to be more susceptible to plasma exposure at shorter distances. This finding suggests that fungi, eukaryotic cells, may demand more specific treatment parameters to be inhibited.

Plasma antimicrobial efficiency for the three microorganisms was compared. To avoid inactivation zones malformation, the treatments were performed keeping the flow rate at 2.0 SLM and the distance at $2.0 \mathrm{~cm}$. At this distance the plasma plume touches the surface and spreads over it allowing active species to reach further regions. The inhibition zone area as a function of treatment time for each microorganism is presented in Fig. 5. All microorganisms exhibit a linear increase of inactivation zones with no saturation even at $180 \mathrm{~s}$ treatment. The Gram-positive bacterium E. faecalis was the most sensible to plasma effect, followed by the Gram-negative bacterium P. aeruginosa. The yeast C. albicans was the most resistant to plasma treatment. Fungi are provided of very thick and rigid cell wall, which contributes to their considerable resistance to plasma exposure. Variable degree of susceptibility between $E$. faecalis and $P$. aeruginosa may be correlated to the differences between the cell wall structure of Gram positive and Gram negative cells. Markedly, the results suggest that reactive species might be less effective against Gram negative external membrane. However, this hypothesis should be investigated in future studies.

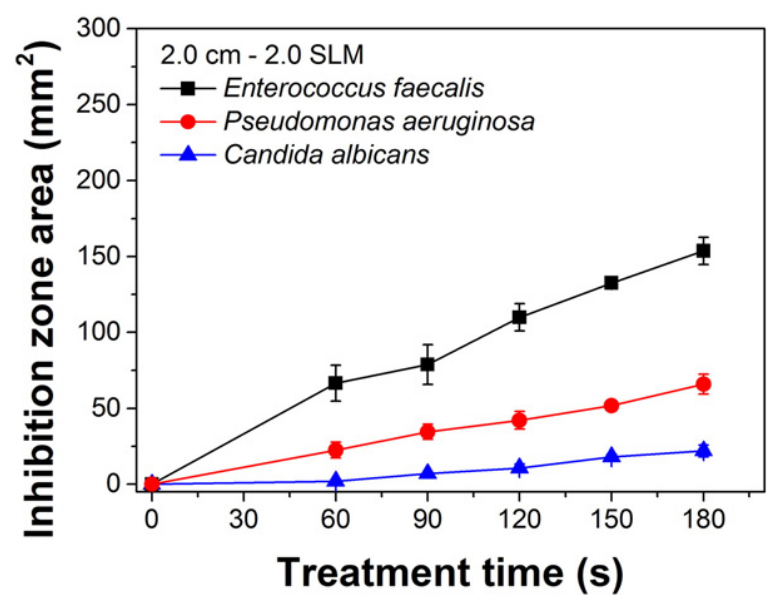

Fig. 5. Inhibition zones for all tested microorganism (Enterococcus faecalis, Pseudomonas aeruginosa and Candida albicans) as a function of the treatment time. 
Several mechanisms are thought to be responsible for microbial inhibition in plasma. Some authors showed that the reactive plasma agents target proteins, DNA, cell wall and membrane. For instance, oxygen species, such as $\mathrm{O}$ and $\mathrm{O}_{3}$ can physically etch the cell membrane and induce DNA deterioration [13]. UV radiation in the wavelength range of 250-500 $\mathrm{nm}$ can also induce damage to DNA [28]. Excessive charge accumulation on microorganisms can lead to cell disruption [29]. After exposition to all active species present in the plasma plume, microorganisms are mostly affected by cell wall damage [30]. Thus, cell morphology of each microorganism was investigated by SEM and the results are presented in Figs. 6-8.

The SEM images showed that plasma jet induced damage to C. albicans, E. faecalis and P. aeruginosa cells. Surface damage and intracellular material loss are evidenced in C. albicans shown in Fig. 6(b). Fig. 7(b) shows changes in cell morphology of E. faecalis. Also, major modifications in $P$. aeruginosa cells structure can be observed in Fig. 8(b), suggesting loss of cellular content.

\section{Conclusions}

The He plasma jet investigated in this study was found to be an efficient microbicide, when tested against three different microbial species. The size of inhibition zones on Petri dishes was much larger

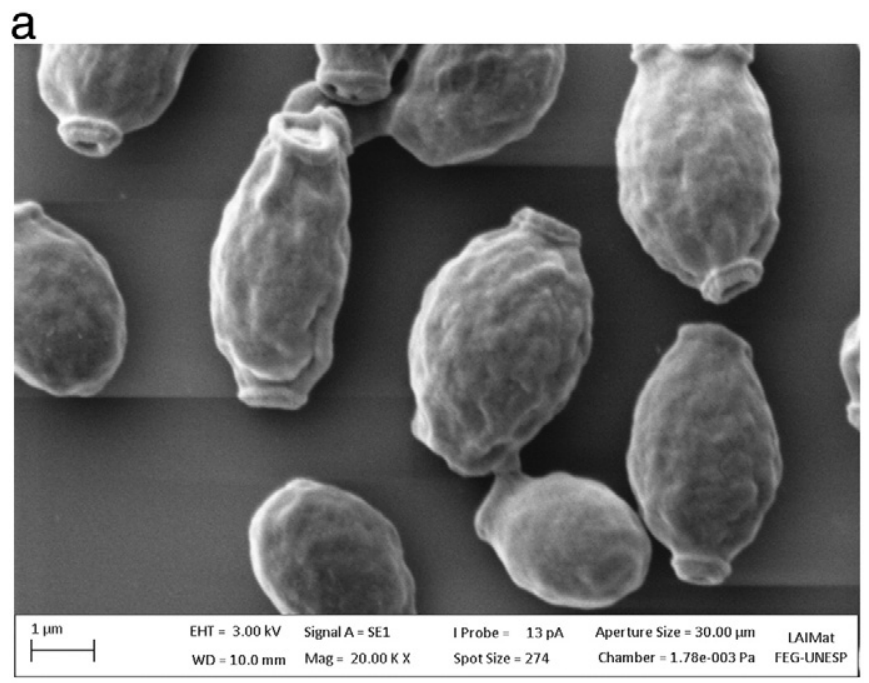

\section{b}

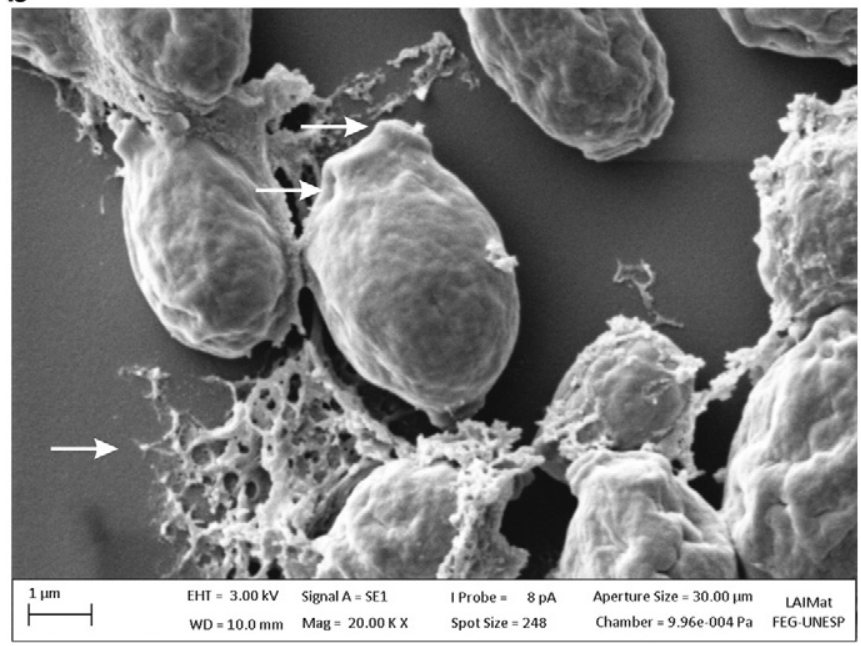

Fig. 6. Scanning electron microscopy of $C$. albicans cells. (a) Cells not exposed to plasma jet $(20,000 \times)$. (b) Cells exposed to plasma jet with arrows indicating surface damage and loss of cellular material.

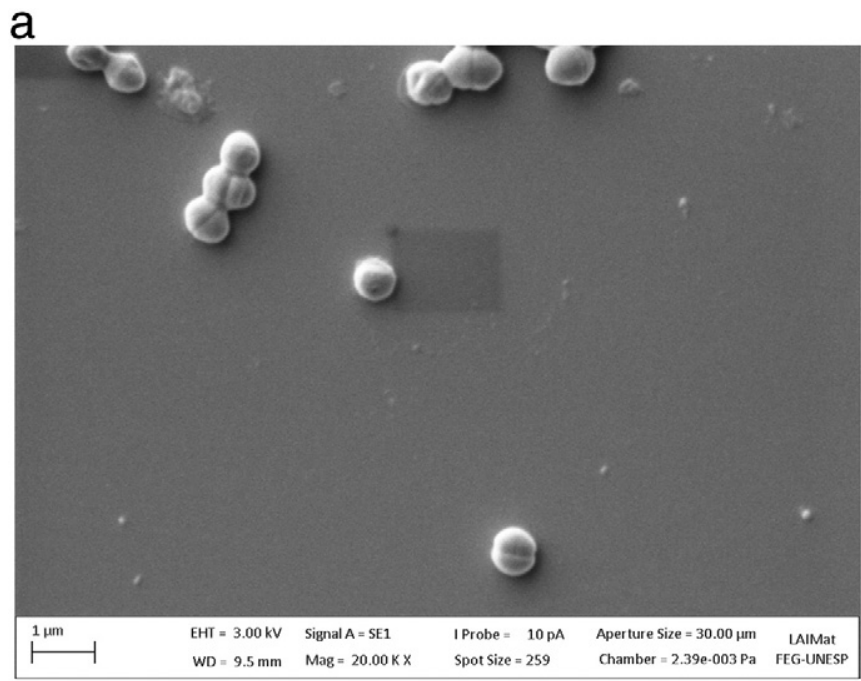

b

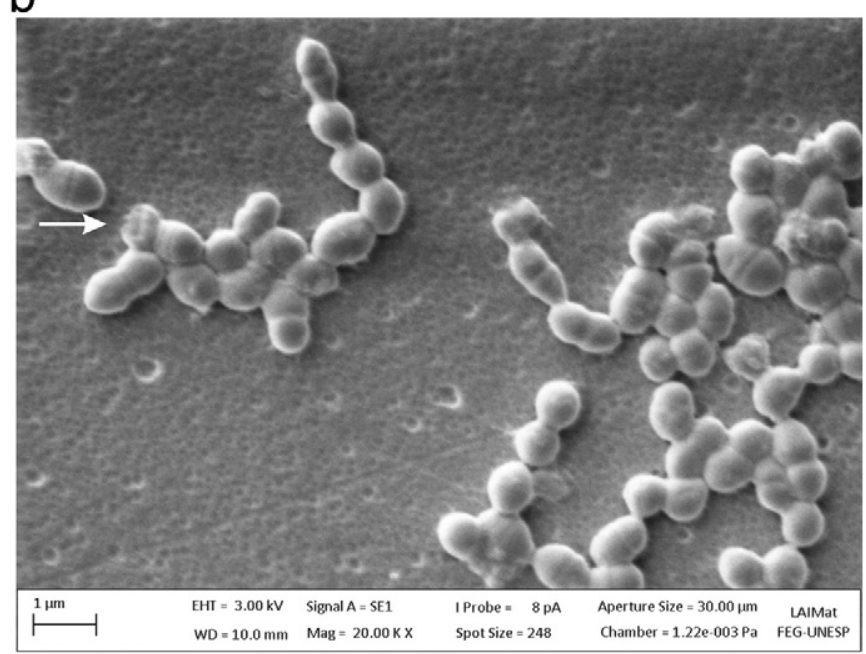

Fig. 7. Scanning electron microscopy of E. faecalis cells. (a) Cells not exposed to plasma jet. (b) Cells exposed to plasma jet indicating change in cell morphology. The arrow indicates loss of cellular integrity.

than the jet diameter, suggesting that ozone, as a long-living species, is the major inactivation agent. Although the gas flow does not significantly influence the size of inhibition zones, their shape and homogeneity were affected. The 2.0 SLM flow presented more uniform zones with circular shape. The Gram-positive bacterium presented the greatest susceptibility to plasma exposure compared to the others microorganisms, while the fungus $C$. albicans showed to be the most resistant. The amount of active species and UV radiation that reach the sample can be controlled varying the distance between the plasma plume and the substrate. The presented results reveal that the distance is an essential parameter for fungi inactivation especially for long treatment time. SEM analysis revealed loss of cells integrity after plasma exposure, suggesting that the process induces membrane damage and leak of cellular content.

\section{Acknowledgments}

The authors acknowledge financial support from Conselho Nacional de Desenvolvimento Científico e Tecnológico (CNPq) under research grant 470995/2013-0 and from São Paulo State Research Foundation (FAPESP) under grant 2014/02354-7. 


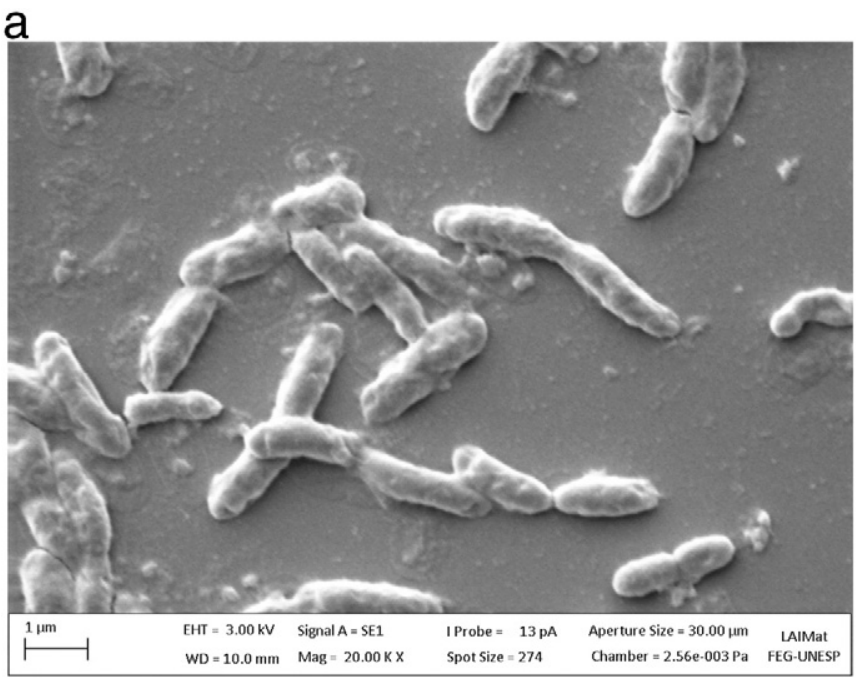

b

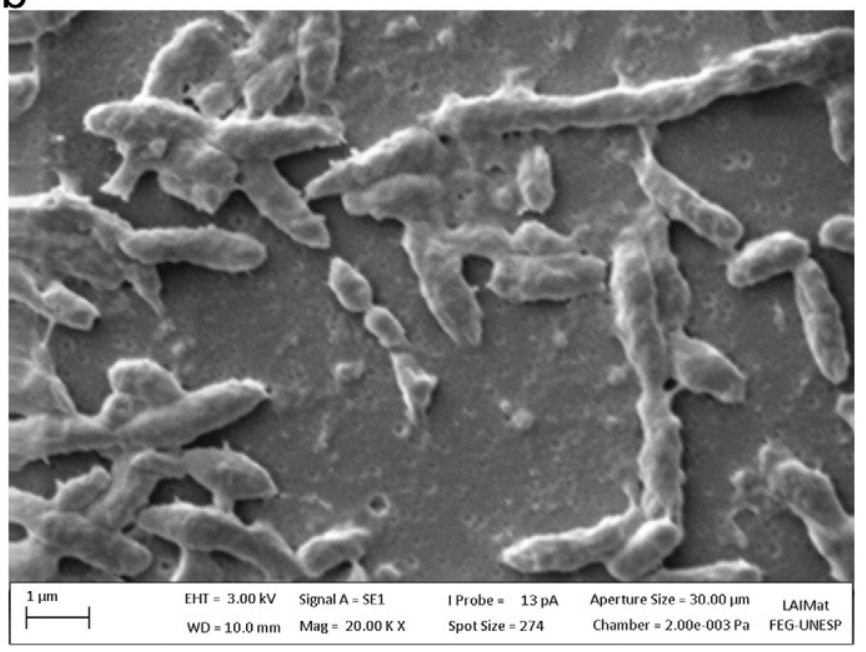

Fig. 8. Scanning electron microscopy of $P$. aeruginosa cells. (a) Cells not exposed to plasma jet. (b) Cells exposed to plasma jet exhibiting change in cell morphology.

\section{References}

[1] C. Tendero, C. Tixier, P. Tristant, J. Desmaison, P. Leprince, Atmospheric pressure plasmas: a review, Spectrochim. Acta B 61 (2006) 2-30.

[2] V. Nehra, A. Kumar, H.K. Dwivedi, Atmospheric non-thermal plasma sources, Int. J. Eng. 2 (2008) 53-68.

[3] A. Schutze, J.Y. Jeong, S.E. Babayan, J. Park, G.S. Selwyn, R.F. Hicks, The atmosphericpressure plasma jet: a review and comparison to other plasma sources, IEEE Trans. Plasma Sci. 26 (1998) 1685-1694.

[4] X. Lu, M. Laroussi, V. Puech, On atmospheric-pressure non-equilibrium plasma jets and plasma bullets, Plasma Sources Sci. Technol. 21 (2012) 1-17.

[5] I. Koban, R. Matthes, N.-O. Hübner, A. Welk, P. Meisel, B. Holtfreter, R. Sietmann, E. Kindel, K.-D. Weltmann, A. Kramer, T. Kocher, Treatment of Candida albicans biofilms with low-temperature plasma induced by dielectric barrier discharge and atmospheric pressure plasma jet, New J. Phys. 12 (2010) 1-16.

[6] K. Fricke, I. Koban, H. Tresp, L. Jablonowski, K. Schröder, A. Kramer, K.-D. Weltmann, T. von Woedtke, T. Kocher, Atmospheric pressure plasma: a high-performance tool for the efficient removal of biofilms, PLoS One 7 (2012) 1-8.
[7] M.Y. Alkawareek, S.P. Gorman, W.G. Grahan, B.F. Gilmore, Potential cellular targets and antibacterial efficacy of atmospheric pressure non-thermal plasma, Int. J. Antimicrob. Ag. 43 (2014) 154-160.

[8] Y. Nasruddin, K. Nakajima, E. Mukai, H.S.E. Komatsu, M. Rahayu, T. Nur, H. Ishijima, Y. Enomoto, J. Uesugi, T. Sugama, Nakatani, a simple technique to improve contractile effect of cold plasma jet on acute mouse wound by dropping water, Plasma Process. Polym. 12 (2015) 1-12.

[9] H. Kuwahata, T. Yamaguchi, R.-I. Ohyama, A. Ito, Inactivation of Escherichia coli using atmospheric-pressure plasma jet, Jpn. J. Appl. Phys. 54 (2015) 1-6.

[10] M.Y. Alkawareek, Q.T. Algwari, G. Laverty, S.P. Gorman, W.G. Graham, D. O'Connell, B.F. Gilmore, Eradication of Pseudomonas aeruginosa biofilms by atmospheric pressure non-thermal plasma, PLoS One 7 (2012) 1-7.

[11] P.P. Sedghizadeh, M.T. Chen, C. Schaudinn, A. Gorur, C. Jiang, Inactivation kinetics study of an atmospheric-pressure cold-plasma jet against pathogenic microorganisms, IEEE Trans. Plasma Sci. 40 (2012) 2879-2882.

[12] M. Lee, H. Kim, Y. Kim, W.-Y. Lee, K.Y. Baik, N.K. Kaushik, G. Cho, Blood coagulation with atmospheric-plasma jets, IEEE Int. Conf. Plasma Sci. 2P-159 (2012).

[13] A. Mai-Prochnow, A.B. Murphy, K.M. McLean, M.G. Kong, K. Ostrikov, Atmospheric pressure plasmas: infection control and bacterial response, Int. J. Antimicrob. Ag. 43 (2014) 508-517.

[14] G.M. Xu, X.M. Shi, J.F. Cai, S.L. Chen, P. Li, C.W. Yao, Z.S. Chang, G.J. Zhang, Dual effects of atmospheric pressure plasma jet on skin wound healing of mice, Wound Repair Regen. 23 (2015) 878-884.

[15] K.-D. Weltmann, E. Kindel, T. von Woedtke, M. Hähnel, M. Stieber, R. Brandenburg Atmospheric-pressure plasma sources: prospective tools for plasma medicine, Pure Appl. Chem. 82 (2010) 1223-1237.

[16] H. Yamazaki, T. Ohshima, Y. Tsubota, H. Yamaguchi, J. Jayawardena, Y. Nishimura Microbicidal activities of low frequency atmospheric pressure plasma jets on oral pathogens, Dent. Mater. J. 30 (2011) 384-391.

[17] K. Wende, P. Williams, J. Dalluge, W. van Gaens, H. Aboubakr, J. Bischof, T. von Woedtke, S.M. Goyal, K.-D. Weltmann, A. Bogaerts, K. Masur, P.J. Bruggeman, Identification of the biologically active liquid chemistry induced by a nonthermal atmospheric pressure plasma jet, Biointerphases 10 (2015) 1-16

[18] S. Reuter, J. Winter, S. Iséni, A. Schmidt-Bleker, M. Dünnbier, K. Masur, K. Wende, K.D. Weltmann, The influence of feed gas humidity versus ambient humidity on atmospheric pressure plasma jet-effluent chemistry and skin cell viability, IEEE Trans. Plasma Sci. 43 (2014) 3185-3192.

[19] J.W. Lackman, S. Schneider, E. Edengeiser, F. Jarzina, S. Brinckmann, E. Steinborn, M Havenith, J. Benedikt, J.E. Bandow, Photons and particles emitted from cold atmospheric-pressure plasma inactivate bacteria and biomolecules independently and synergistically, J. R. Soc. Interface 10 (2014) 1-12.

[20] M.Y. Alkawareek, Q.T. Algwari, S.P. Gorman, W.G. Graham, D. O'Connell, B.F. Gilmore, Application of atmospheric pressure nonthermal plasma for the in vitro eradication of bacterial biofilms, FEMS Immunol. Med. Mic. 65 (2012) 381-384.

[21] E. Dolezalova, P. Lukes, Membrane damage and active but nonculturable state in liquid cultures of Escherichia coli treated with an atmospheric pressure plasma jet, Bioelectrochemistry 103 (2015) 7-14.

[22] T.J. Silhavy, D. Kahne, S. Walker, The bacterial cell envelope, Cold Spring Harb. Perspect. Biol. 2 (2010) 1-16.

[23] J. Ruiz-Herrera, Fungal Cell Wall: Structure, Synthesis, and Assembly, second ed. CRC Press, Boca Raton, 2012.

[24] K.G. Kostov, A.C. Borges, C.Y. Koga-Ito, T.M.C. Nishime, V. Prysiazhnyi, R.Y. Honda, Inactivation of Candida albicans by cold atmospheric pressure plasma jet, IEEE Trans. Plasma Sci. 43 (2015) 770-775.

[25] X. Pei, X. Lu, J. Liu, D. Liu, Y. Yang, Inactivation of a $25.5 \mu \mathrm{m}$ Enterococcus faecalis biofilm by a room-temperature, battery-operated, handheld air plasma jet, J. Phys. D. Appl. Phys. 45 (2012) 1-5.

[26] C.-T. Liu, C.-J. Wu, Y.-W. Yang, Z.-H. Lin, J.-S. Wu, S.-C. Hsiao, C.-P. Lin, Atomic oxygen and hydroxyl radical generation in round helium-based atmospheric-pressure plasma jets by various electrode arrangements and its application in sterilizing Streptococcus mutans, IEEE Trans. Plasma Sci. 42 (2014) 3830-3836.

[27] J. Goree, B. Liu, D. Drake, Gas flow dependence for plasma-needle disinfection of S. mutans bacteria, J. Physics D Appl. Phys. 39 (2006) 3479-3486.

[28] J.-W. Lackmann, J.E. Bandow, Inactivation of microbes and macromolecules by atmospheric-pressure plasma jets, Appl. Microbiol. Biotechnol. 98 (2014) 6205-6213.

[29] E. Stoffels, "Tissue processing" with atmospheric plasmas, Contrib. Plasma Phys. 47 (2007) 40-48.

[30] K. Kim, H.J. Ahn, J.-H. Lee, J.-H. Kim, S.S. Yang, J.-S. Lee, Cellular membrane collapse by atmospheric-pressure plasma jet, Appl. Phys. Lett. 104 (2014) 1-3. 